\title{
Virtual Patient Encounter
}

National Cancer Institute

\section{Source}

National Cancer Institute. Virtual Patient Encounter. NCI Thesaurus. Code C150759.

A patient encounter where the patient and the practitioner(s) are not in the same physical location and the interaction takes place by electronic means. 